https://doi.org/10.15407/ujpe64.5.392

V.I. VISHNYAKOV, S.A. KIRO, M.V. OPRYA, O.D. CHURSINA, A.A. ENNAN

Physical-Chemical Institute for Environment and Human Protection,

Min. Edu. Sci. and Nat. Acad. of Sci. of Ukraine

(3, Preobrazhens'ka Str., Odesa 65082,Ukraine; e-mail: eksvar@ukr.net)

\title{
FORMATION OF PARTICLES IN WELDING FUME PLASMAS: NUMERICAL MODELING AND EXPERIMENT
}

\begin{abstract}
Formation of particles in a fume plasma obtained from the gas metal arc welding is investigated by the numerical modeling of the plasma evolution. The model of welding fume plasma evolution includes the following processes: vapor emission from the arc zone and mixing with a shielding gas, plasma formation, nucleation, nucleus growth via the material condensation and coalescence, solidification of liquid droplets into primary particles, and coagulation of primary particles into inhalable particles in the breathing zone. The computed results are compared with experimental data on the specific surface area, chemical composition, and dependence of the particle sizes on the shielding gas temperature.
\end{abstract}

Ke ywords: gas metal arc welding, numerical modeling, particle size distribution, chemical composition.

\section{Introduction}

Arc welding usage is accompanied by the emission of welding materials' vapors. The high-temperature welding fume vapor is ionized via electron-atom collisions and the UV-radiation from the arc. Therefore, all processes occur in an ionized gas, i.e. in a plasma. Vapors mix with a shielding gas and air and are cooled down with the condensation into liquid droplets named nuclei. After the nucleus growth via the material condensation and coalescence, these droplets are solidified and form the solid primary particles of a welding fume. The coagulation of primary particles forms inhalable particles in the breathing zone.

The numerical modeling of the all arc welding processes intensively develops in the last years. The electric arc [1, 2], metal joining [3, 4], and fume formation $[5,6]$ are the modeled objects. The last mentioned process arouses a particular interest, since it is related to environmental problems. Inhalable particles have the complex chemical composition, frequently unhealthy, and represent toxicological and ecological dangers. Therefore, they demand an attentive studying.

Many authors study the nucleation in a plasma by the numerical simulation (see, e.g., Refs. [7-9]). The

(C) V.I. VISHNYAKOV, S.A. KIRO, M.V. OPRYA,

O.D. CHURSINA, A.A. ENNAN, 2019 numerical simulation allows studying the behavior of the process depending on environmental parameters and initial conditions $[10,11]$. This allows one to find out which processes determine the fume formation rate $[12,13]$, as well as the morphology and the chemical composition of welding fume particles $[14,15]$.

The presented paper is devoted to the numerical modeling of the formation of primary and inhalable particles in a fume from the gas metal arc welding (GMAW). The modeled object is the single gas parcel of a vapor-gas mixture, whose evolution under the cooling with regard for the initial temperature and the chemical composition of a vapor is calculated. Such modeling allows describing the delicate processes during the welding fume formation, in particular, studying the welding fume particle size distribution, chemical composition, and morphology. A simplified algorithm for the calculation in PTC Mathcad Prime is presented in Appendix [16].

The size of nucleus droplets is much less than the mean free path of plasma particles, and the Knudsen number $K n \gg 1$. Therefore, the growth of nuclei and their coagulation should be considered within the gas kinetic theory. This consideration remains valid for the initial stage of the coagulation of solid primary particles. However, the Knudsen number decreases in the process of growth of agglomerates, and the last stage of their coagulation into inhalable particles should be considered in the diffusion approach.

ISSN 2071-0194. Ukr. J. Phys. 2019. Vol. 64, No. 5 


\section{Plasma Formation}

The high-temperature metal vapors from the weld materials mix up with a shielding gas under the welding torch nozzle. The numerical simulation [17] demonstrates that the average gas temperature in the boundary region at the torch outlet $T \sim 2500 \mathrm{~K}$. This means that the nucleation occurs in a vapor-shielding gas mixture, before the mixing with air.

The vapor temperature and UV-radiation from the welding arc provide the ionization of atoms in the vapor-gas mixture, i.e. the system should be considered as a plasma, in which the ionization balance is described by the Saha equation with account for the photo-ionization [18]:

$\frac{n_{e} n_{i}}{n_{a}}=\frac{\Sigma_{i}}{\Sigma_{a}} \nu_{e} \exp \frac{-I}{k_{\mathrm{B}} T}+\frac{\pi r_{a}^{2} j_{p h}}{\gamma_{e i}} \equiv K_{S}$,

where $n_{e}, n_{i}$, and $n_{a}$ are the average for the local thermodynamic equilibrium (LTE) region number densities of electrons, ions, and atoms, respectively; $n_{a}=n_{A}-n_{i}, n_{A}$ is the initial atom number density; $\Sigma_{i}$ and $\Sigma_{a}$ are the ion and atom statistical weights;

$\nu_{e}=2\left(\frac{m_{e} k_{\mathrm{B}} T}{2 \pi \hbar^{2}}\right)^{3 / 2}$

is the effective density of electron states; $I$ is the atom ionization potential; $k_{\mathrm{B}}$ is the Boltzmann constant; $T$ is the absolute temperature; $m_{e}$ is the electron mass; $\hbar$ is the Planck constant; $r_{a}$ is the ionizable atom radius; the electron-ion recombination coefficient $\gamma_{e i} \sim 10^{-6} \mathrm{~cm}^{3} / \mathrm{s}[19] ; j_{p h} \sim 10^{16} \mathrm{~cm}^{-2} \mathrm{~s}^{-1}$ is the photon flux; and $K_{S}$ is the Saha constant.

The electrical neutrality of the equilibrium plasma is described by the following expression:

$n_{e}=n_{i}=n_{0}$,

where $n_{0}$ is the unperturbed number density, which is determined from Eq. (1) for a multicomponent system as

$n_{0}=\sum_{j} \frac{K_{S j}}{2}\left(\sqrt{1+4 \frac{n_{A j}}{K_{S j}}}-1\right)$,

$n_{A j}$ is the initial atom number density of ionizable components (without ionization). In the vapor-gas mixture, we have [20]

$n_{A j}=\frac{P}{k_{\mathrm{B}} T} \frac{g_{j 0}}{\mu_{j}}\left[\sum \frac{g_{j 0}}{\mu_{j}}+\frac{1}{\mu_{s g}} \frac{T_{0}-T}{T-T_{s g}}\right]^{-1}$,

ISSN 2071-0194. Ukr. J. Phys. 2019. Vol. 64, No. 5 where $P$ is the atmospheric pressure; $g_{j 0}$ is the initial $j$ th component mass fraction in vapors (it is determined by the content of weld material components); $\mu_{j}$ is the $j$ th component molecular mass; and $\mu_{s g}$ is the shielding gas molecular mass $\left(\mathrm{CO}_{2}\right.$ in the system under consideration). The temperature evolution is described by the equation

$T=T_{s g}+\left(T_{0}-T_{s g}\right) \exp \frac{-t}{\tau}$,

where $T_{0}$ is the initial vapor temperature; $T_{s g}$ is the shielding gas temperature; $\tau$ is the mixing time scale, which is dependent on the evaporation of materials from a welding wire and a molten pool and on the mechanism of welding and shielding gas mixing. This parameter is determined by the comparison of the calculated values with experimental data. In the system under consideration, $\tau=1.7 \mathrm{~ms}$, which has been determined by coincidence of the calculated and measured chemical compositions of particles.

At the shielded metal arc welding (SMAW), the additional agents of potassium and sodium with low ionization potential (for potassium, $I_{K}=4.3 \mathrm{eV}$ )) are inserted into the plasma from an electrode cover, and they determine the plasma ionization. The welding fumes obtained from GMAW do not contain the alkali additional agent. The condensable atoms are the source of ions. The thermal ionization rate for condensable atoms is lower than for alkali metals, because the ionization potential is higher (for iron $I_{\mathrm{Fe}}=7.9 \mathrm{eV}$ ). The equilibrium number densities of the ions, which are obtained from condensable materials, are presented in Fig. 1 for initial component mass fractions, which are determined by the welding wire composition: $g_{\mathrm{Fe}}=96.5 \%$ for iron; $g_{\mathrm{Mn}}=2 \%$ for manganese; $g_{\mathrm{Si}}=1 \%$ for silicon; $g_{\mathrm{Cu}}=0.5 \%$ for copper.

The nuclei as liquid droplets appear in the welding fume after the nucleation. Such a system should be considered as a dusty plasma, i.e. the plasma, which contains the solid or liquid particles as a dust component $[21,22]$. The interphase interaction leads to the particle charging. The surface of a charged particle is the additional channel for the ionization of gas atoms. Therefore, there is an ionization balance displacement in the space charge region (SCR) around the particle $[18,23,24]$. 


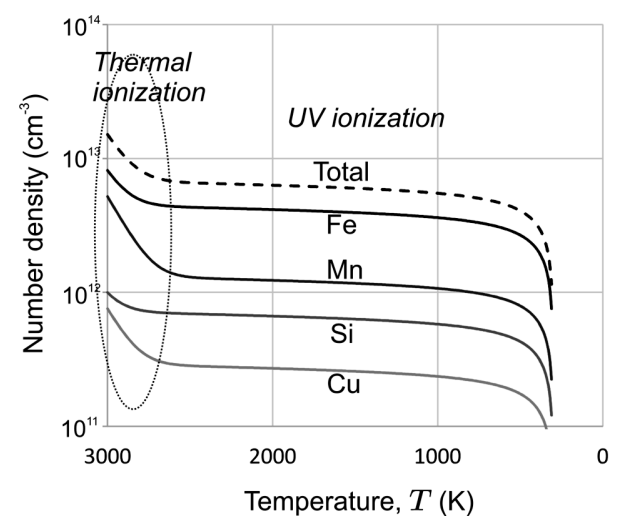

Fig. 1. Evolutions of the equilibrium ion number densities under the vapor-gas mixture cooling, when GMAW is used [18]

In this case, the electrical neutrality is described by the expression

$n_{e}-n_{i}=z_{p} n_{p}$

where $n_{p}$ is the particle average number density; $z_{p}$ is their average charge number (in units of the elementary charge), the average electron and ion number densities are determined as $n_{e}=n_{p} N_{e W}$ and $n_{i}=n_{p} N_{i W} ; N_{e W}$ and $N_{i W}$ are the numbers of electrons and ions in a Wigner-Seitz cell, which is a sphere with radius $R_{W}=\left(3 / 4 \pi n_{p}\right)^{1 / 3}$ around the particle with radius $r_{p}$ :

$N_{e W}=4 \pi n_{0} \int_{r_{p}}^{R_{W}} r^{2} \frac{\exp 2 \Phi(r)}{2 \cosh \Phi(r)-1} d r$,
$N_{i W}=4 \pi n_{0} \int_{r_{p}}^{R_{W}} r^{2} \frac{\exp [-2 \Phi(r)]+2 \sinh \Phi(r)}{2 \cosh \Phi(r)-1} d r$,

where $\Phi=e \varphi / k_{\mathrm{B}} T$ is the dimensionless potential of the electric field, and, hence, the particle charge

$z_{p}=N_{e W}-N_{i W}$

Equations (7) and (8) are described in details in Ref. [18], where the nonequilibrium ionization is considered. The potential distribution for a particle with radius $r_{p} \ll r_{D}$ (where $r_{D}=\sqrt{k_{\mathrm{B}} T / 8 \pi e^{2} n_{0}}$ is the screening length, and $r_{D} \sim 1 \mu \mathrm{m}$ in the system under consideration) is determined by the relation

$\tanh \frac{r_{p} e \varphi(r)}{r_{D} k_{\mathrm{B}} T}=\tanh \frac{r_{p} V_{b}}{r_{D} k_{\mathrm{B}} T} \frac{r_{p}}{r} \exp \frac{r_{p}-r}{r_{D}}$.
We note that the nucleus has negative charge, and the potential barrier $\left(V_{b}\right)$ on the particle-plasma boundary is [18]

$V_{b} \cong \frac{2}{5} k_{\mathrm{B}} T \ln \frac{n_{e s}}{n_{0}} \quad\left(n_{e s}<n_{0}\right)$,

where $n_{e s}$ is the surface electron number density

$n_{e s}=\nu_{e} \exp \frac{-W}{k_{\mathrm{B}} T}+\frac{Y j_{p h}}{v_{T e}}$

$Y$ is the quantum yield; $v_{\mathrm{Te}}=\sqrt{8 k_{\mathrm{B}} T / \pi m_{e}}$ is the thermal velocity of electrons; $W$ is the electron work function with regard for the dependence of the work function on the particle size [25]

$W=W_{0}+\frac{0.39 e^{2}}{r_{p}}$,

where $W_{0}$ is the work function for a flat surface.

The environmental parameters are calculated on each iteration step by the subprogram

$n_{a}, n_{e}, n_{i}, n_{0}, z_{p}, S=\operatorname{ENVIRONMENT}\left(T, r_{p}, n_{p}, X\right)$,

where $S$ is the vapor supersaturation; $X$ is the matrix, which contains the particle component composition for the multicomponent condensation [26]. The supersaturation $(S)$, atom $\left(n_{a}\right)$ and ion $\left(n_{i}\right)$ number densities also are matrices, which consider all vapor components. Therefore, such parameters as the density, specific heat, or viscosity of a vapor-gas mixture can be calculated at any time moment of the process.

\section{Nucleation}

The welding fume formation is a result of the heterogeneous ion-induced nucleation in the environment enriched by electrons. Thus, there is the energy and charge exchanges between a nucleus and the environment. Such consideration has been proposed in Refs. [27-29], where a change in the Gibbs free energy as a result of the nucleation takes the form

$\Delta G=4 \pi r_{n}^{2} \gamma-\frac{4}{3} \pi r_{n}^{3} \frac{\rho k_{\mathrm{B}} T \ln S}{m_{c a}}+E_{\gamma}+E_{\mathrm{ex}}+E_{q}$,

where $r_{n}$ is the nucleus radius; $\gamma=\gamma_{0} r_{n} /\left(r_{n}+2 \delta\right)$ is the surface free energy of the nucleus; $\gamma_{0}$ is the surface free energy of the flat surface; $\delta$ is the Tolman

ISSN 2071-0194. Ukr. J. Phys. 2019. Vol. 64, No. 5 
length; $m_{c a}$ is the mass of a condensable atom; $\rho$ is the nucleus density; and $S$ is the supersaturation of the condensable material.

In Eq. (11), the first two terms describe a change in the Gibbs free energy determined by the classical nucleation theory $[30,31]$. The term $E_{\gamma}$ is a change in surface free energy as a result of the appearance of an electrical double layer on the nucleus surface:

$E_{\gamma}=-\frac{z_{n} V_{b}}{2}$

$E_{\text {ex }}$ is a change in the Gibbs free energy as a result of the interphase energy exchange:

$E_{\mathrm{ex}}=-z_{n}\left(W_{n}+\frac{3}{2} k_{\mathrm{B}} T\right)$

$E_{q}$ is a change in the Gibbs free energy as a result of the nucleus charging; it has different definitions for a conductor and a dielectric:

$E_{q m}=\frac{e^{2}}{2}\left[\frac{z_{n}^{2}}{r_{n}}+\frac{1}{r_{n}}-\frac{1}{r_{i}}\right]-$ for a conductor,

$E_{q d}=\frac{e^{2}(\varepsilon-1)}{2 \varepsilon} \times$

$\times\left[\frac{6}{5} \frac{z_{n}^{2}}{(\varepsilon-1) r_{n}}+\frac{1}{r_{n}}-\frac{1}{r_{i}}\right]-$ for a dielectric,

where $z_{n}$ is the nucleus charge number; $\varepsilon$ is the dielectric constant; $r_{i}$ is the radius of a single-charged positive ion, which induced the nucleation.

The two kinds of nuclei are formed by the heterogeneous ion-induced nucleation: the equilibrium nuclei with radius $r_{\text {eq }}$, which are in the equilibrium with the environment; and the nonequilibrium critical nuclei with radius $r_{\mathrm{cr}}$, which appear as a result of fluctuations. The radius of the equilibrium nucleus is determined as a minimum of the function $\Delta G\left(r_{n}\right)$, and the radius of the critical nucleus is determined as the maximum of the function $\Delta G\left(r_{n}\right)$.

The equilibrium nucleus is in the stable stage, and some activation energy is necessary for the nucleus growth $E_{\text {act }}=\Delta G\left(r_{\mathrm{cr}}\right)-\Delta G\left(r_{\mathrm{eq}}\right)$. This activation energy decreases down to zero $\left(E_{\text {act }} \rightarrow 0\right)$ with the vapor-gas mixture cooling. Thus, the equilibrium and critical radii tend to the same value $\left(r_{\mathrm{eq}} \rightarrow r_{\mathrm{cr}}\right)$. After that, the unrestricted growth of nuclei begins, until the condensable materials deplete.
The number density of equilibrium nuclei with radius $r_{n}=r_{\text {eq }}$ is determined in the following form [29]:

$n_{n}=\frac{n_{a 0}}{N_{a n}+N_{a n}^{-3 / 2} \exp \frac{\Delta G\left(r_{\mathrm{eq}}\right)}{k_{\mathrm{B}} T}}$,

where $n_{a 0}$ is the initial (prior to the nucleation start) condensable atom number density; $N_{a n}$ is the number of atoms in one nucleus: $N_{a n}=4 \pi \rho r_{n}^{3} / 3 m_{c a}$.

The nucleation is calculated by the subprogram

$r_{\mathrm{eq}}, r_{\mathrm{cr}}, n_{n}, N_{a n}, E_{\mathrm{act}}=$

$=\operatorname{NUCLEATION}\left(T, n_{a}, n_{0}, S, X\right)$,

where all arguments except $T$ are the matrices, and the nucleus charges are calculated inside the subprogram.

The disappearance of condensable atoms should be taken into account, while nucleation occurs. Thus, it is necessary to subtract the number of atoms in nuclei $n_{n} N_{a n}$ from the equilibrium number of condensable atoms $n_{A}$. The matrix $X$ is used for the multicomponent nucleation: $n_{A}^{\prime}=n_{A}-n_{n} N_{a n} X$.

The evolutions of the equilibrium and critical radii at the vapor-gas mixture cooling are presented in Fig. 2, $a$, and the evolutions of the unperturbed number density and the nucleus number density are presented in Fig. 2, $b$.

The nucleus number density is much higher than the unperturbed one and, accordingly, ion number density. However, the ions are centers of the ion-induced nucleation, and their number should correspond to the number of nuclei. When the nucleation occurs, ions disappear from the gas phase, and the electron-ion recombination is replaced by the neutralization of nuclei with a much greater collision cross-section. As a result, the balance between ionization and recombination is broken in favor of ionization, and new electrons and ions appear in the plasma. Thus, a new equilibrium state for nuclei and the gas phase arises. The ionization balance stabilization time is $\sim 10^{-9} \mathrm{~s}$.

The calculation of the nucleation is stopped, when the growth activation energy $E_{\text {act }}=0$, i.e. $r_{\text {eq }}=r_{\mathrm{cr}}$. After that, the nucleus growth calculation begins.

\section{Droplet Growth}

The growth of nucleus with radius $r_{n}$ is determined by the increment in the mass due to the adsorp- 


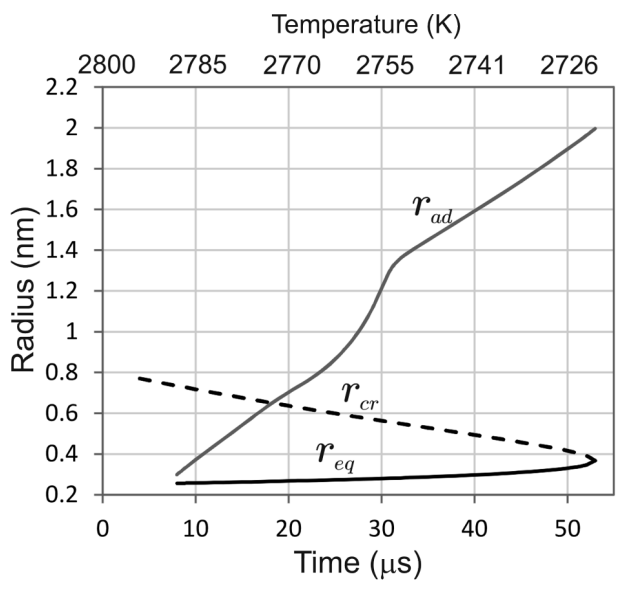

$a$

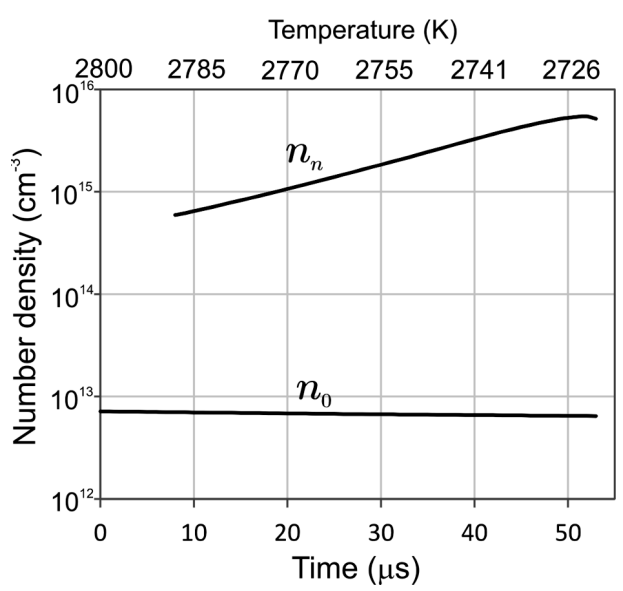

$b$

Fig. 2. Evolutions of the equilibrium nucleus $r_{\text {eq }}$, critical nucleus $r_{\mathrm{cr}}$, and aggregated droplet $r_{a d}$ radii $(a)$; unperturbed $n_{0}$ and nucleus $n_{n}$ number densities $(b)$

tion and transpiration fluxes difference, which is described in the free molecular regime by the equation $[32,33]$

$\frac{d m_{n}}{d t}=\alpha_{c} \pi r_{n}^{2} v_{T a} m_{c a}\left(n_{c a}-n_{c s}\right)$,

where $\alpha_{c}$ is the evaporation-condensation coefficient [34]; $v_{\mathrm{Ta}}=\sqrt{8 k_{\mathrm{B}} T / \pi m_{a}}$ is the thermal velocity of condensable atoms; $m_{c a}$ is the mass of a condensable atom; $n_{c a}$ is their number density; $n_{c s}$ is the number density of condensable atoms near the nucleus surface: $n_{c s}=n_{c a} S_{R} / S ; S$ is the current supersaturation; $S_{R}=P_{\text {sat }}\left(r_{n}\right) / P_{\text {sat }}(\infty)$ is a change in the vapor partial pressure with regard for the surface curvature and the interphase interaction, which follows from Eq. (11):

$$
\begin{aligned}
& \ln S_{R} \cong \frac{m_{c a}}{4 \pi \rho k_{\mathrm{B}} T} \times \\
& \times\left[8 \pi \gamma_{0} \frac{r_{n}+3 \delta}{\left(r_{n}+2 \delta\right)^{2}}-\frac{z_{n}\left(V_{b}+W\right)}{r_{n}^{3}}-\frac{e^{2}\left(1-z_{n}^{2}\right)}{2 r_{n}^{4}}\right] .
\end{aligned}
$$

The change in the nucleus radius as a result of the growth is

$$
\frac{d r_{n}}{d t}=\frac{1}{4 \pi r_{n}^{2} \rho} \frac{d m_{n}}{d t}=\frac{\alpha_{c} v_{T a} m_{c a} n_{c a}}{4 \rho}\left(1-\frac{S_{R}}{S}\right) .
$$

This equation describes the nucleus growth by the condensation of the predominant vapor component, i.e. iron. However, the condensation of other components exists prior to the beginning of the basic growth.

After the nucleation of the predominant component, the fluxes of accompanying low-boiling components onto the iron nucleus appear, because the partial pressure of these components at the nucleus surface is zero. Therefore, the condensation of these components on the nucleus droplet occurs, but the growth of a nucleus by the condensation of iron is absent, because $r_{\mathrm{eq}}<r_{\mathrm{cr}}$. The change in the number of atoms of the $j$ th component in the multicomponent droplet is described by the equation [26]

$\frac{d N_{a j}}{d t}=\alpha_{c j} \pi r_{n}^{2} v_{T j} n_{a j}\left(1-X_{j} \frac{S_{R j}}{S_{j}}\right)$,

where $X_{j}$ is the $j$ th component fraction.

Then the change in the nucleus droplet radius is

$\frac{d r_{n}}{d t}=\sum_{j}\left[\frac{\alpha_{c j} v_{T j} m_{a j} n_{a j}}{4 \rho_{j}}\left(1-X_{j} \frac{S_{R j}}{S_{j}}\right)\right]$.

At the initial moment of the nucleation, the content of accompanying low-boiling components in the nucleus $X_{j \neq F e}=0$. Therefore, the growth of a nucleus droplet by the deposition of these components on the nucleus surface takes place.

The condensation growth of nuclei is calculated by the subprogram

$d r, X=\operatorname{GROWTH}\left(k, d t, T, n_{a}, S, r_{k}, z_{k}, V_{b k}, X\right)$,

where $k$ is the kind of particle growth: $k=0$ for the nucleus growth, when $r_{n}>r_{\mathrm{cr}} ; k=1$ for the growth of aggregated droplets, when $r_{a d}>r_{\mathrm{cr}} ; k=2$ for the condensation of low-boiling components on nuclei, when $r_{n}<r_{\text {cr }}$ (iron condensation is excluded).

ISSN 2071-0194. Ukr. J. Phys. 2019. Vol. 64, No. 5 


\section{Droplet Coalescence}

The large number density of nuclei $n_{n} \sim 10^{15_{-}}$ $10^{16} \mathrm{~cm}^{-3}$ (see Fig. 2, b) causes their intense Brownian collisions and the coagulation, because it has a thermodynamic cause [35]. Since the nuclei are in the liquid state, their coagulation is a coalescence. As a result, the aggregated droplets, which grow through the coalescence and condensation, which is described by Eq. (15), are formed. However, it is necessary to take into account that the nucleation continues, and the thermodynamics of the system requires the presence of nuclei with the equilibrium number density (12). Therefore, the number and size of nuclei cannot be changed via the coalescence, because new nuclei appear. This requirement is removed after the nucleation termination.

Thus, already at the initial stage of the nucleation, the bimodal size distribution of droplets occurs. The first mode contains the droplets of nuclei; aggregated droplets resulting from the long-term coalescence and condensation represent the second mode. It should be noted that, in this case, the nucleation is the original "pump" for the transfer of atoms from the gas phase into the aggregated droplets, and the intensity of this process is higher than the vapor condensation intensity (15) on aggregated droplets [36]. These droplets can be described by a log-normal size distribution, which is based on the number of atoms $N$ contained in the droplets, by using the probability density function for two modes [37]

$$
\begin{aligned}
& f_{N}=\frac{n_{n}}{N \sqrt{2 \pi} \ln \sigma_{n}} \exp \frac{-\left(\ln N-\ln N_{0 n}\right)^{2}}{2 \ln ^{2} \sigma_{n}}+ \\
& +\frac{n_{c d}}{N \sqrt{2 \pi} \ln \sigma_{c d}} \exp \frac{-\left(\ln N-\ln N_{0 c d}\right)^{2}}{2 \ln ^{2} \sigma_{c d}}
\end{aligned}
$$

where the index $n$ is used for nuclei, index $c d$ is used for coagulated droplets; $N_{0}=\bar{N} \exp \left(-\ln ^{2} \sigma / 2\right)$ is the median of the distribution; $\sigma$ is the standard deviation; $\bar{N}$ is the average number of atoms in the droplets, for which the equation of conservation for atoms is as follows:

$N_{c a}=n_{n} \bar{N}_{n}+n_{c d} \bar{N}_{c d}$.

The evolution of such a system can be described by the integral moments of the distribution (16) [3840]. The numerical calculation of the coagulation of particles is the complicated problem. Therefore, the approximation method based on the moments of the size distribution was proposed in Ref. [41]. The moments are described by the equation

$M(k)=\int_{0}^{\infty} N^{k} f_{N} d N$,

and the Brownian coagulation can be described as [42]

$\frac{\partial M(k)}{\partial t}=\frac{1}{2} \int_{0}^{\infty} f_{N} \int_{0}^{\infty} \beta\left(N, N^{\prime}\right) f_{N^{\prime}} \times$
$\times\left[\left(N+N^{\prime}\right)^{k}-N^{k}-N^{\prime k}\right] d N^{\prime} d N$,

where $N$ and $N^{\prime}$ are the numbers of atoms in the colliding droplets; and $\beta\left(N, N^{\prime}\right)$ is the collision kernel. The Brownian collision kernel can be determined by the kinetic theory of gases or by the diffusion theory according to a droplet size. If the droplets are much smaller than the mean free path of gas particles, the gas kinetic theory should be used to determine the collision kernel [7]

$\beta\left(N, N^{\prime}\right)=\beta_{0}\left(N^{1 / 3}+N^{\prime 1 / 3}\right)^{2} \sqrt{\frac{N+N^{\prime}}{N N^{\prime}}}$,

$\beta_{0}=\left(\frac{3 m_{c a}}{4 \pi \rho}\right)^{1 / 6} \sqrt{\frac{6 k_{\mathrm{B}} T}{\rho}}$,

where the Coulomb interaction is neglected, because $e^{2} z z^{\prime} /\left(a+a^{\prime}\right) \ll k_{\mathrm{B}} T$ ( $a$ is the $r_{n}$ or $r_{a d} ; z$ is the $z_{n}$ or $z_{a d}$, respectively).

The evolution of moments (17) can be determined for each mode (16). The zero moments represent the total number densities of generated particles $n_{n}$ and $n_{a d}$. The total numbers of atoms are determined by the first moments. As a result, the average number of atoms in the droplets of each mode is

$\bar{N}_{n}=\frac{M_{n}(1)}{M_{n}(0)}, \quad \bar{N}_{c d}=\frac{M_{c d}(1)}{M_{c d}(0)}$,

and the standard deviations are defined by the equations

$\ln ^{2} \sigma_{n}=\ln \frac{M_{n}(0) M_{n}(2)}{M_{n}(1)^{2}}, \ln ^{2} \sigma_{c d}=\ln \frac{M_{c d}(0) M_{c d}(2)}{M_{c d}(1)^{2}}$.

Equations (16)-(19) allow us to describe the evolution of the coalescence in the bimodal system of 


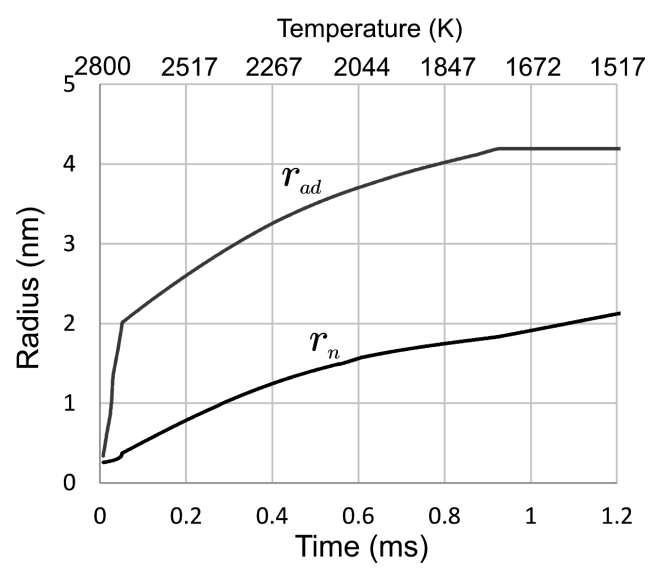

$a$

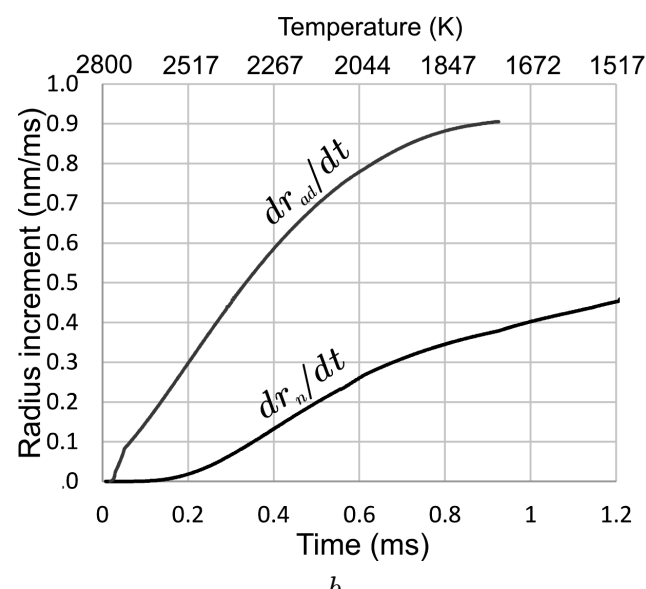

$b$

Fig. 3. Evolutions of the average radii $(a)$ and radius increments $(b)$

droplets with regard for the intramodal coalescence and the intermodal association of the different droplet modes. The coalescence is calculated by three individual subprograms:

$n_{2}, \bar{N}_{2}, \sigma_{2}=\operatorname{PUMP}\left(d t, \beta_{0}, n_{1}, \bar{N}_{1}, \sigma_{1}, n_{2}, \bar{N}_{2}, \sigma_{2}\right)$

for the calculation of the coalescence at the nucleation, whose result is demonstrated in Fig. 2, $a$, where the evolution of the average radius of aggregated droplets $r_{a d}=\left(3 m_{c a} \bar{N}_{2} / 4 \pi \rho\right)^{1 / 3}$ is presented;

$n_{1}, \bar{N}_{1}, \sigma_{1}, n_{2}, \bar{N}_{2}, \sigma_{2}=$

$=\operatorname{BIMODAL}\left(d t, \beta_{0}, n_{1}, \bar{N}_{1}, \sigma_{1}, n_{2}, \bar{N}_{2}, \sigma_{2}\right)$

for the calculation of the coalescence at the nucleus growth;

$n_{1}, \bar{N}_{1}, \sigma_{1}=\operatorname{UNIMODAL}\left(d t, \beta_{0}, n_{1}, \bar{N}_{1}, \sigma_{1}\right)$ for the calculation of the nucleus coalescence after the solidification of aggregated droplets.

The last subprogram is necessary to account for the dependence of the solidification temperature on the droplet size [43]. The droplets of the second mode (aggregated droplets) are solidified earlier than the droplets of the first mode (nuclei); and the transient stage exists, when the second mode is represented by solid particles, but the first mode is the liquid droplets. The bimodal coalescence terminates, when the aggregated droplets become solid particles. There is only the coalescence of the first mode.

The time, for which the number of droplets decreases twice, is $\left(2 \beta_{0} \times 10^{15} \mathrm{~cm}^{-3}\right)^{-1} \sim 8 \mu$ s at the temperature of $2000 \mathrm{~K}$. Therefore, the calculation time step of $0.1 \mu \mathrm{s}$ corresponds to much smaller changes in the number of droplets due to the coalescence. Since the calculation time step of the equilibrium state is $1 \mu \mathrm{s}$, the cycle from ten consecutive calculations of the moments was used on each step of the main program.

\section{Calculation of the Primary Particle Formation}

The calculation results are presented in Figs. 35 . Evolutions of the average radii of nuclei and aggregated droplets with regard for increase in the condensation and coagulation are presented in Fig. 3, a. In addition, the evolutions of radius increments due to the condensation growth only (see Eq. (15)) are presented in Fig. 3, $b$. The cooling of the vapor-gas mixture to the temperature of solidification of aggregated droplets occurs during $0.9 \mathrm{~ms}$. After that, this mode is not changed via the coalescence or vapor condensation, only the nucleus growth is proceeds.

Evolutions of the chemical compositions are presented in Fig. 4, $a$ for nuclei and in Fig. 4, $b$ for aggregated droplets. They are characterized by a gradual decrease in the iron content and by an increase in the mass fractions of other elements. The solidification of aggregated droplets at a time of $0.9 \mathrm{~ms}$ stops their growth and, accordingly, a change in the chemical composition. The nuclei growth and change in the chemical composition is prolonged up to $1.2 \mathrm{~ms}$. Therefore, the iron content in solid primary particles of the different modes is different.

Solid primary particles with the bimodal size distribution, which is presented in Fig. 5, appear in a

ISSN 2071-0194. Ukr. J. Phys. 2019. Vol. 64, No. 5 
welding fume after the solidification of nuclei and aggregated droplets. In the system under consideration, the primary particles have parameters presented in Table 1 . The content of iron in the primary particles, which are formed from aggregated droplets, is higher than in the primary particles from the nuclei and strongly depends on the vapor-gas mixture cooling rate determined by the mixing time scale $\tau$ in Eq. (5). In the case under consideration, this time is $\tau=1.7 \mathrm{~ms}$, which ensures the contents of iron to be $77 \%$ in the nuclei with the average diameter $d_{n}=4.3 \mathrm{~ms}$ and $84 \%$ in the aggregated droplets with the average diameter $d_{c d}=8.4 \mathrm{~nm}$. The increase in the time scale up to $3 \mathrm{~ms}$ provides the contents of iron to be $54 \%$ in the nuclei with the average diameter $d_{n}=5.8 \mathrm{~nm}$ and $76 \%$ in the aggregated droplets with the average diameter $d_{c d}=10.5 \mathrm{~nm}$. Thus, the chemical composition of primary particles depends on their size and the vapor-gas mixture cooling rate [44].

\section{Coagulation of Solid Primary Particles}

The agglomerates generated from solid primary particles are irregular structures; therefore, the radius of an agglomerate, which contains $N$ primary particles (monomers), is given by

$r_{\mathrm{ag}}=a N^{1 / D_{\mathrm{f}}}$

where $a$ is the radius of monomers; $D_{\mathrm{f}}$ is the fractal dimension ( $D_{\mathrm{f}}=3$ for a perfect sphere). In this case, the collision kernel for the free molecule regime without the electrical interaction between particles is

Table 1. Parameters of the particle size distributions for two shielding gas temperatures

\begin{tabular}{|l|c|c|c|c|}
\hline \multirow{2}{*}{ Particles } & \multicolumn{4}{|c|}{ Temperature } \\
\cline { 2 - 5 } & \multicolumn{2}{|c|}{$300 \mathrm{~K}$} & \multicolumn{2}{c|}{$600 \mathrm{~K}$} \\
\cline { 2 - 5 } & Primary & Inhalable & Primary & Inhalable \\
\hline$d_{1}(\mathrm{~nm})$ & 4.3 & 185 & 4.8 & 202 \\
$n_{1}\left(\mathrm{~cm}^{-3}\right)$ & $6 \times 10^{14}$ & $3.9 \times 10^{5}$ & $5.6 \times 10^{14}$ & $3.6 \times 10^{5}$ \\
$\sigma_{1}$ & 2.4 & 1.5 & 2.6 & 1.5 \\
$d_{2}\left(\mathrm{~nm}^{*}\right)$ & 8.4 & 209 & 9.5 & 239 \\
$n_{2}\left(\mathrm{~cm}^{-3}\right)$ & $4 \times 10^{13}$ & $2.8 \times 10^{4}$ & $3.7 \times 10^{13}$ & $2.6 \times 10^{4}$ \\
$\sigma_{2}$ & 2.5 & 1.6 & 2.5 & 1.7 \\
\hline
\end{tabular}

Temperature (K)

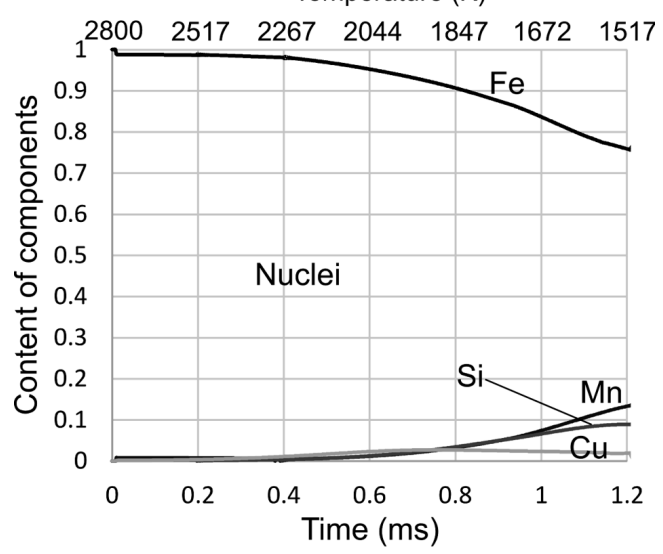

$a$

Temperature (K)

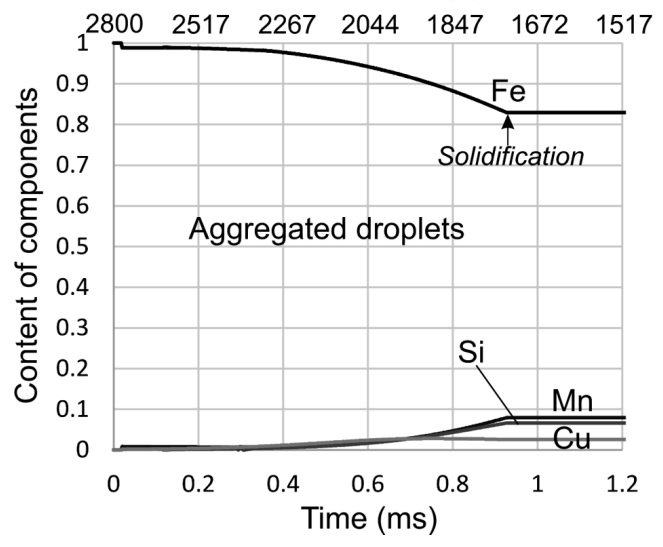

$b$

Fig. 4. Evolution of the chemical composition: nucleus droplets $(a)$ and aggregated droplets $(b)$

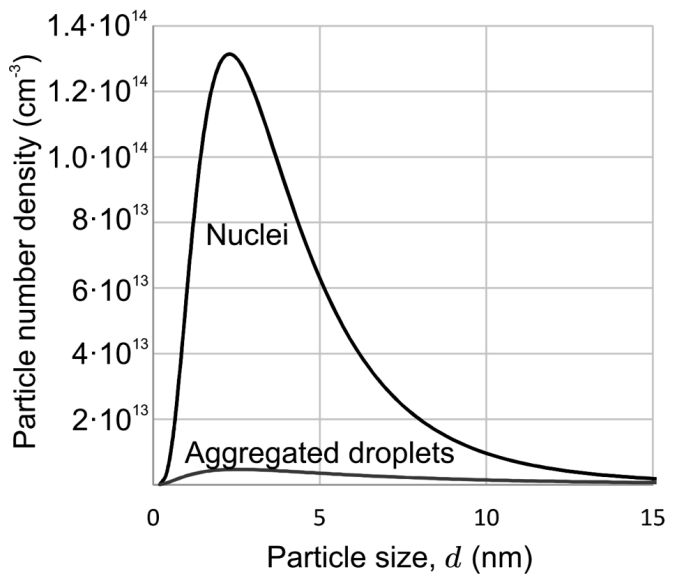

Fig. 5. Number-based primary particle size distribution 


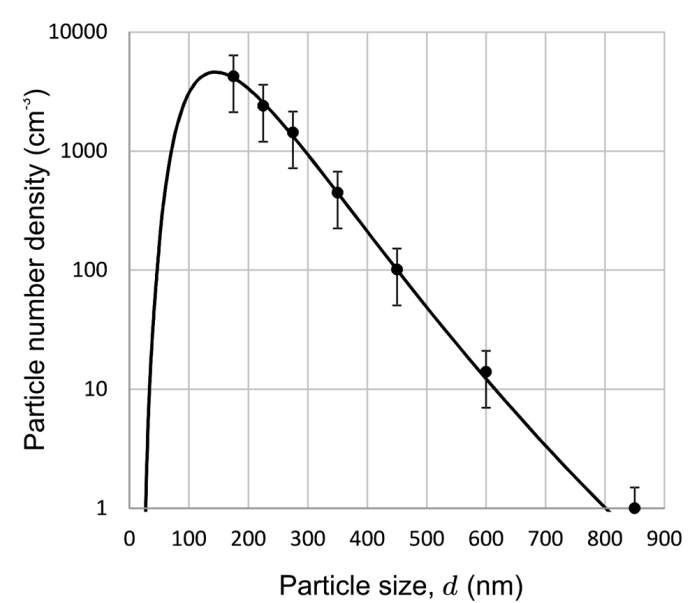

Fig. 6. Number-based total inhalable particle size distribution for $T_{s g}=300 \mathrm{~K}$ : black line is the numerical modeling result, dots are the average experimental data (error lines are the variability of measured values)

described by the equation [45]:

$\beta\left(N, N^{\prime}\right)=\beta_{0} \sqrt{\frac{N+N^{\prime}}{N N^{\prime}}}\left(N^{1 / D_{\mathrm{f}}}+N^{\prime 1 / D_{\mathrm{f}}}\right)^{2}$,

$\beta_{0}=\sqrt{\frac{6 k_{\mathrm{B}} T a}{\rho}}$,

where $\rho$ is the monomer density; $N$ and $N^{\prime}$ are the numbers of monomers in the colliding agglomerates with fractal dimension $D_{\mathrm{f}}$.

The collision kernel for charged particles is [46]

$\beta_{Q}\left(N, N^{\prime}\right)=\beta\left(N, N^{\prime}\right) \exp \frac{-U_{N, N^{\prime}}}{k_{\mathrm{B}} T}$,

where $U_{N, N^{\prime}}$ is the interaction energy on the shortest distance between the interacting particles, which can be considered in the Coulomb approximation

$U_{N, N^{\prime}}=\frac{e^{2} z_{N} z_{N^{\prime}}}{a\left(N^{1 / D_{\mathrm{f}}}+N^{\prime 1 / D_{\mathrm{f}}}\right)}$,

where $z_{N}$ and $z_{N^{\prime}}$ are the particle charge numbers.

As follows from the potential distribution (10), the electric field created by a charged agglomerate is

$E_{s}=\frac{k_{\mathrm{B}} T r_{D}}{2 e r_{\mathrm{ag}}^{2}} \sinh \frac{2 r_{\mathrm{ag}} V_{b}}{r_{D} k_{\mathrm{B}} T}$.

On the other hand, the Gauss theorem implies that $E_{s}=e z_{\mathrm{ag}} / r_{\mathrm{ag}}^{2}$. Therefore, the charge of an agglom- erate, whose radius is much less than $r_{D}$ can be described by the relation

$z_{N}=\frac{k_{\mathrm{B}} T r_{D}}{2 e^{2}} \sinh \frac{2 a N^{1 / D_{\mathrm{f}}} V_{b}}{r_{D} k_{\mathrm{B}} T}$,

which is equal to one determined by Eq. (9), if the particle has equilibrium charge. Under the condition $r_{\mathrm{ag}} V_{b} \ll r_{D} k_{\mathrm{B}} T$, this charge can be described as $z_{N} \cong$ $\cong a N^{1 / D_{\mathrm{f}}} V_{b} / e^{2}$.

The resulting collision kernel is

$\beta_{Q}\left(N, N^{\prime}\right)=\beta\left(N, N^{\prime}\right) \exp \frac{-a_{N, N^{\prime}} V_{b N} V_{b N^{\prime}}}{e^{2} k_{\mathrm{B}} T}$,

where $a_{N, N^{\prime}}=a\left(N N^{\prime}\right)^{1 / D_{\mathrm{f}}}\left(N^{1 / D_{\mathrm{f}}}+N^{\prime 1 / D_{\mathrm{f}}}\right)^{-1}$.

The coagulation of agglomerates leads to an increase in their sizes up to values, which exceed the mean free path length, and Eq. (22) becomes inapplicable. In this case, the collision kernel should be described in the diffusion regime:

$$
\begin{aligned}
& \beta_{Q}\left(N, N^{\prime}\right)=\frac{2 k_{\mathrm{B}} T C\left(a_{N, N^{\prime}}\right)}{3 \eta} \frac{a\left(N^{1 / D_{f}}+N^{\prime 1 / D_{f}}\right)}{a_{N, N^{\prime}}} \times \\
& \times\left(1+\frac{a_{N, N^{\prime}} V_{b N} V_{b N^{\prime}}}{e^{2} k_{\mathrm{B}} T}\right),
\end{aligned}
$$

where $\eta$ is the viscosity; $C(a)$ is the Cunningham slip correction [47]

$C(a)=1+\frac{\lambda}{a}\left(1.142+0.588 \exp \frac{-a}{\lambda}\right)$,

and $\lambda=67 \mathrm{~nm}$ is the mean free path.

The calculation is based on the method of moments with the collision kernel (22) or (23), by taking into account that the coagulation occurs in both ways of collisions between particles: the intramodal and intermodal ones (Subprogram BIMODAL). The resulting inhalable particles also have the bimodal size distribution (see Table 1), which correlates with experimental data (see Fig. 6).

\section{Comparison to Experimental Data and Discussion}

For the comparison of the computed results with experimental data, two experimental equipment configurations were used: the first one described in Ref. [20] and the second, whose scheme is presented in

ISSN 2071-0194. Ukr. J. Phys. 2019. Vol. 64, No. 5 
Fig. 9. The power source is a Paton PSI-250R invertor rectifier. The ER 70S-6 welding wire is $0.8 \mathrm{~mm}$ in diameter. The inverse polarity direct current is $90 \pm 5 \mathrm{~A}$; voltage is $21 \pm 0.5 \mathrm{~V}$; and wire feed speed is $7 \pm 0.5 \mathrm{~cm} / \mathrm{s}$. At a distance of $20 \mathrm{~cm}$ from the arc, the welding fume was extracted with an air co-flow of $1.7 \mathrm{~m}^{3} / \mathrm{min}$.

The calculation of the inhalable particle formation is based on the question about fractal dimension. The experimental data on the effect of a shielding gas temperature on the particle size distribution are presented in Ref. [20]. The search for the matching between experimental data and the results of calculations leads to the fractal dimension $D_{f 1}=1.95$ for the first mode and $D_{f 2}=2.25$ for the second mode. The usage of these values for the calculation in Eqs. (22) and (23) gives a good agreement with experimental data, which are presented in Fig. 7.

The change in the shielding gas temperature is considered in all calculations including the nucleation. The calculations of the formation of primary particles and their coagulation give the values, which are presented in Table 1 [16]. The vapor-gas mixture cooling rate decreases, as the shielding gas temperature increases, because the term $\left(T_{0}-T_{s g}\right)$ in Eq. (5) decreases. Therefore, the duration of the growth of particles via the vapor condensation and coalescence increases, which leads to an increase in the particle sizes. The particle sizes increase, and the particle number density decreases under a decrease in the cooling rate in the process of growth of particles via the vapor condensation, which was demonstrated also in Ref. [7].

It should be noted that the formation of primary particles occurs in the representative volume of $1 \mathrm{~cm}^{3}$. A similar volume for inhalable particles is that of the breathing zone of about $1 \mathrm{~m}^{3}$. The inhalable particle first mode formation lasts for $0.5 \mathrm{~ms}$, and this duration for the second mode is $7 \mathrm{~ms}$.

The used values of the fractal dimension mean that the first-mode agglomerates are the homogeneous grape-like structures, which contain mostly primary particles from nuclei; and the second-mode agglomerates are closer to the heterogeneous grapelike structures, which contain both modes of primary particles. This assumption corresponds to the modeled data from Refs. [13, 48], where similar particle structures are presented, and with experimental data from Ref. [49], where transmission electron mi-

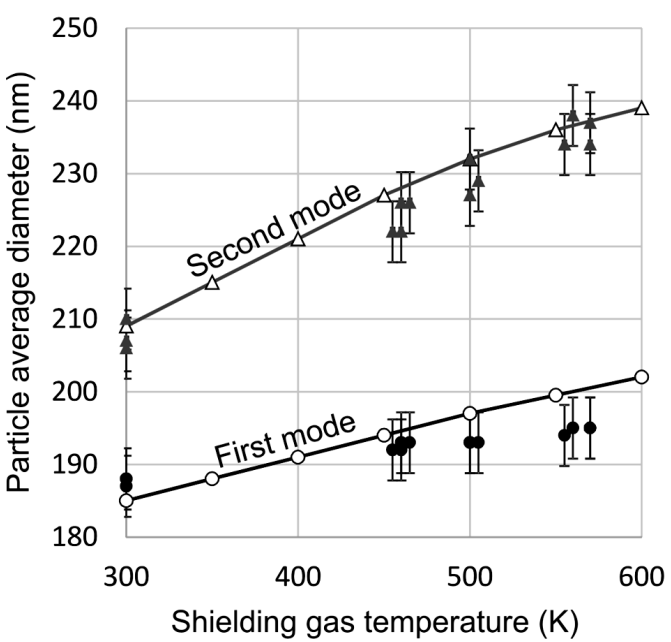

Fig. 7. Dependences of average inhalable particle sizes on the shielding gas temperature: dots are the experimental data from [20]; lines are the calculation results [16]

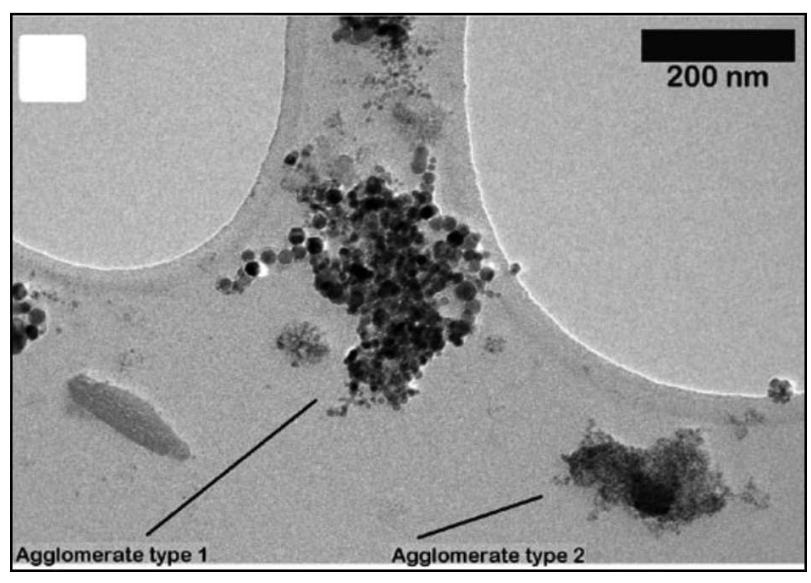

Fig. 8. TEM image of two different agglomerate types [49]

croscopy (TEM) images are presented, and the two types of agglomerates were detected (see Fig. 8). In this case, the agglomerate of type 1 in Fig. 8 corresponds to the second mode of inhalable particles in the system under consideration, and the agglomerate of type 2 corresponds to the first mode.

For the additional comparison, the GMAW fume was separated into two fractions by a grid-type electrostatic precipitator. The precipitator consists of two sections: the charging section and the grid section shown together in Fig. 9a. The charging section in the form of a corona discharge ionizer [50] is located above the grid section. The negative voltage on 


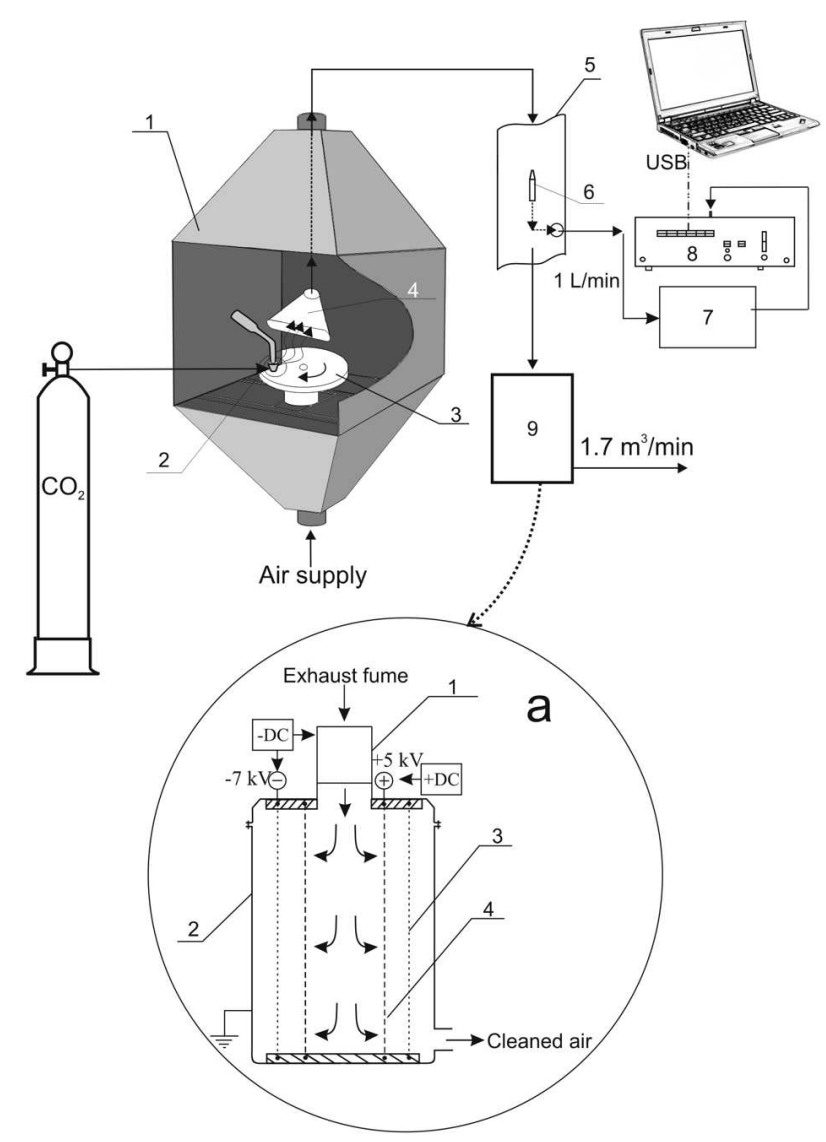

Fig. 9. Experimental equipment scheme: fume chamber (1); welding torch (2); turntable (3); slit air inlet (4); vertical pipe (5); nozzle for the isokinetic sampling (6); dual-stage aerosol dilution system (7); laser aerosol spectrometer (8); electrostatic precipitator (9). Fig. 9a. Grid-type electrostatic precipitator scheme: charging section (1); grid section (2); fine filter (3); coarse filter (4)

Table 2. Experimental data and calculation results

\begin{tabular}{|l|c|c|c|c|}
\hline \multirow{2}{*}{ Parameter } & \multicolumn{2}{|c|}{ Experiment } & \multicolumn{2}{c|}{ Calculation } \\
\cline { 2 - 5 } & $\begin{array}{c}\text { Fine filter, } \\
\text { Coarse filter } \\
\text { downstream }\end{array}$ & $\begin{array}{c}\text { Coarse } \\
\text { filter } \\
\text { upstream }\end{array}$ & Nuclei & $\begin{array}{c}\text { Aggregated } \\
\text { droplets }\end{array}$ \\
\hline Particle size, nm & 187 & 208 & 4.3 & 8.4 \\
Mass fraction, \% & 72 & 28 & 71 & 29 \\
As, m ${ }^{2} / \mathrm{g}$ & 29.5 & 16.8 & 33 & 16 \\
Content of Fe, \% & 78.3 & 85.4 & 77 & 84 \\
Content of Mn, \% & 12.7 & 10.3 & 13 & 8 \\
Content of Si, \% & 8.2 & 4.0 & 9 & 6 \\
Content of Cu, \% & 0.8 & 0.3 & 1 & 2 \\
\hline
\end{tabular}

the inner multineedle discharge electrode is equal to $7 \mathrm{kV}$, resulting in a total corona current of $0.6 \mathrm{~mA}$ with the fume flowing, which provides the negative charging of fume particles.

The grid section is mounted in the filter holder assembly and consists of two metallic coaxial cylindertype filters with the interspace of $3 \mathrm{~cm}$. The coarse filter with a diameter of $14 \mathrm{~cm}$ is the perforated metal plate with circular holes of diameter $1.2 \mathrm{~mm}$ and open area $27 \%$. The positive potential of a coarse filter is $5 \mathrm{kV}$. The fine filter with a diameter of $20 \mathrm{~cm}$ is the wire mesh with a mesh opening of $0.063 \mathrm{~mm}$, wire diameter of $0.04 \mathrm{~mm}$, and open area $37 \%$. The negative potential of a fine filter is $7 \mathrm{kV}$. The precipitator collection efficiency was about $99 \%$.

The deposits of welding fume particles on the upstream face of a coarse filter preferentially contain particles of the second mode, whereas the first-mode particles are deposited on a fine filter and on the downstream face of a coarse filter as a result of the electric force acting on them in the direction opposing the fume flow.

After the filtration, the three powder samples were analyzed by a Quantachrome Autosorb-6B (Quantachrome Instruments, Boynton Beach, FL, USA) to determine the specific surface area $\left(A_{S}\right)$. The values found by the Brunauer-Emmett-Teller (BET) method are presented in Table 2 together with calculated values. There exists a satisfactory correlation between the calculated and experimental data.

These three powder samples also were analyzed by the method of atomic absorption spectroscopy with a Saturn-3P1 device (Optron Instrument-Making Plant, Minsk, Belarus) for the determination of a chemical composition. The recalculation on the initial elements, which are contained in the welding wire, i.e. with the exclusion of oxygen and carbon, gives the results presented in Table 2, where the calculated chemical composition is also presented. The chemical composition of particles depends on their sizes. This correlation is caused by the dependence of the evaporation/condensation rate on the surface curvature, which is determined by Eq. (13). The different modes of primary particles have different compositions, which is caused by the difference in the solidification temperatures. This difference in the chemical compositions remains in the inhalable particle modes, despite the averaging over numerous primary particles that form every agglomerate.

ISSN 2071-0194. Ukr. J. Phys. 2019. Vol. 64, No. 5 


\section{Conclusions}

The evolution of the processes in the plasma of a welding fume from GMAW is investigated via the numerical modeling. This allowed us to determine the primary particle size distribution, chemical composition, inhalable particle morphology, and size distribution. Both primary and inhalable particles have the bimodal size distribution. The number density of nucleus mode primary particles (average size of $\sim 4 \mathrm{~nm}$ ) greatly exceeds that for the aggregated droplet mode (average size of $\sim 8 \mathrm{~nm}$ ) number density. The content of iron in the particles of the aggregated droplet mode is higher than for the nucleus mode, because iron is partially substituted by manganese and silicon.

The search for a matching between the calculation results and experimental data allowed defining the fractal dimensions of inhalable particles. Apparently, the first inhalable particle mode can be identified as the grape-like homoaggregates; and the second mode as the grape-like heteroaggregates. The different types of agglomerates contain different numbers and kinds of the primary particles, which reflects the mechanism of their formation.

Thus, using the experimental data for the improvement of the fume evolution modeling allowed us to describe the delicate processes during welding fume formation, in particular, the size-based characterization of the chemical composition of welding fume particles, which is of importance for the prevention of occupational diseases in welders.

\section{APPENDIX}

Algorithm of calculation of formation of primary particles

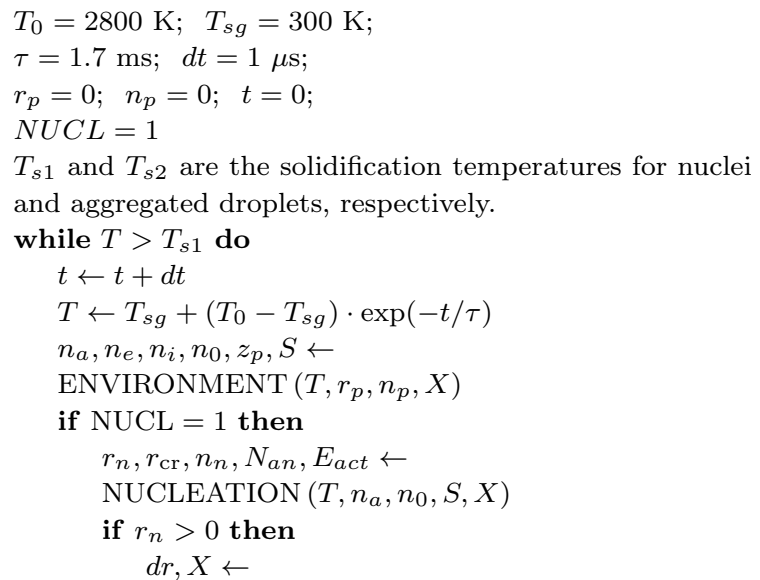

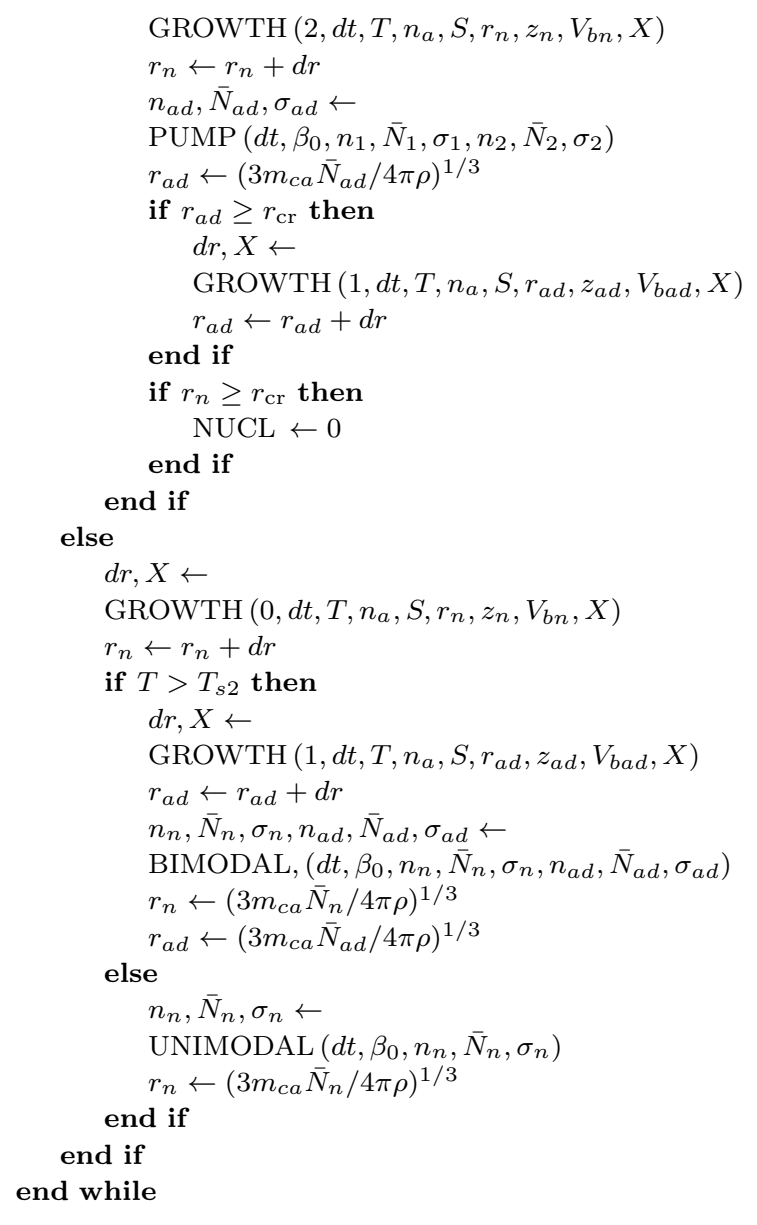

1. I.L. Semenov, I.V. Krivtsun, U. Reisgen. Numerical study of the anode boundary layer in atmospheric pressure arc discharges. J. Phys. D: Appl. Phys. 49, 105204 (2016).

2. F. Yang, M. Rong, Y. Wu, H. Sun, R. Ma, C. Niu. Numerical simulation of the eddy current effects on the Arc splitting process. Plasma Sci. Technol. 14, 974 (2012).

3. M. Islam, A. Buijk, M. Rais-Rohani, K. Motoyama. Simulation-based numerical optimization of arc welding process for reduced distortion in welded structures. Finite Elem. Anal. Design 84, 54 (2014).

4. D.V. Kiran, S.-J. Na. Numerical studies on submerged arc welding process. J. Weld. Joining 32(4), 1 (2014).

5. S. Tashiro, M. Tanaka. Modeling of fume formation process in Arc welding. Transact. Join. Weld. Res. Inst. 40(2), 21 (2011)

6. M. Boselli, V. Colombo, E. Ghedini, M. Gherardi, P. Sanibondi. Two-dimensional time-dependent modelling of fume formation in a pulsed gas metal arc welding process. J. Phys. D: Appl. Phys. 46, 224006 (2013). 
7. M. Shigeta, T. Watanabe, H. Nishiyama. Numerical investigation for nano-particle synthesis in an RF inductively coupled plasma. Thin Solid Films 457, 192 (2004).

8. S.L. Girshick, S.J. Warthesen. Nanoparticles and plasmas. Pure and Appl. Chem. 78, 1109 (2006).

9. I. Denysenko, N.A. Azarenkov. Formation of vertically aligned carbon nanostructures in plasmas: numerical modelling of growth and energy exchange. J. Phys. D: Appl. Phys. 44, 174031 (2011).

10. A.B. Murphy, M. Tanaka, K. Yamamoto, S. Tashiro, T. Sato, J.J. Lowke. Modelling of thermal plasmas for arc welding: the role of the shielding gas properties and of metal vapour. J. Phys. D: Appl. Phys. 42, 194006 (2009).

11. M. Schnick, U. Fuessel, M. Hertel, M. Haessler, A. SpilleKohoff, A.B. Murphy. Modelling of gas-metal arc welding taking into account metal vapour. J. Phys. D: Appl. Phys. 43, 434008 (2010).

12. S. Tashiro, T. Zeniya, A.B. Murphy, M. Tanaka. Visualization of fume formation process in arc welding with numerical simulation. Surface Coat. Technol. 228, S301 (2013).

13. P. Sanibondi. Numerical investigation of the effects of iron oxidation reactions on the fume formation mechanism in arc welding. J. Phys. D: Appl. Phys. 48, 345202 (2015).

14. K.R. Carpenter, B.J. Monaghan, J. Norrish. Influence of shielding gas on fume size morphology and particle composition for gas metal arc welding. Iron Steel Inst. of Japan Intern. 48, 1570 (2008).

15. A. Bogaerts, M. Eckert, M. Mao, E. Neyts. Computer modelling of the plasma chemistry and plasma-based growth mechanisms for nanostructured materials. J. Phys. D: Appl. Phys. 44, 174030 (2011).

16. V.I. Vishnyakov, S.A. Kiro, M.V. Oprya, A.A. Ennan. Effect of shielding gas temperature on the welding fume particle formation: Theoretical model. J. Aerosol Sci. 124, 112 (2018).

17. M. Dreher, U. Füssel and M. Schnik. In Mathematical Modelling of Weld Phenomena Vol. 9 (Technischen Univ. Graz, 2009), p. 127.

18. V.I. Vishnyakov, S.A. Kiro, M.V. Oprya, O.I. Shvetz, A.A. Ennan. Nonequilibrium ionization of welding fume plasmas; Effect of potassium additional agent on the particle formation. J. Aerosol Sci. 113, 178 (2017).

19. A.F. Pal', A.N. Starostin, A.V. Filippov. Charging of dust grains in a nuclear-induced plasma at high pressures. Plasma Phys. Rep. 27(2), 143 (2001).

20. V.I. Vishnyakov, S.A. Kiro, M.V. Oprya, A.A. Ennan. Effects of shielding gas temperature and flow rate on the welding fume particle size distribution. J. Aerosol Sci. 114, 55 (2017).

21. J. Goree. Charging of particles in a plasma. Plasma Sources Sci. Technol. 3, 400 (1994).

22. V.E. Fortov, A.G. Khrapak, S.A. Khrapak, V.I. Molotkov, O.F. Petrov. Dusty plasmas. Phys.-Usp. 47, 447 (2004).

23. V.I. Vishnyakov. Interaction of dust grains in strong collision plasmas: Diffusion pressure of nonequilibrium charge carriers. Phys. Plasmas 12, 103502 (2005).
24. V.I. Vishnyakov. Electron and ion number densities in the space charge layer in thermal plasmas. Phys. Plasmas 13, 033507 (2006).

25. B.M. Smirnov. Processes in plasma and gases involving clusters. Phys.-Usp. 40, 1117 (1997).

26. V.I. Vishnyakov, S.A. Kiro, A.A. Ennan. Multicomponent condensation in the plasma of welding fumes. J. Aerosol Sci. 74, 1 (2014).

27. V.I. Vishnyakov. Homogeneous nucleation in thermal dustelectron plasmas. Phys. Rev. E 78, 056406 (2008).

28. V.I. Vishnyakov, S.A. Kiro, A.A. Ennan. Heterogeneous ion-induced nucleation in thermal dusty plasmas. J. Phys. D: Appl. Phys. 44, 215201 (2011).

29. V.I. Vishnyakov, S.A. Kiro, A.A. Ennan. Formation of primary particles in welding fume. J. Aerosol Sci. 58, 9 (2013).

30. H. Green, W. Lane. Particulate Clouds: Dusts, Smokes and Mists 2nd ed. (Van Nostrand, 1964).

31. P.C. Reist. Introduction to Aerosol Science (Macmillan Publishing, 1984).

32. N.A. Fuchs. Evaporation and Droplet Growth in Gaseous Media, edited by R.S. Bradley (Pergamon Press, 1959).

33. A.T. Zimmer. The influence of metallurgy on the formation of welding aerosols. J. Environ. Monit. 4, 628 (2002).

34. M. Okuyama, J.T. Zung. Evaporation-condensation coefficient for small droplets. J. Chem. Phys. 46, 1580 (1967).

35. V.I. Vishnyakov, G.S. Dragan. Thermodynamic reasons of agglomeration of dust particles in the thermal dusty plasma. Condensed Matter Phys. 6, 687 (2003).

36. V.I. Vishnyakov, S.A. Kiro, A.A. Ennan. Bimodal size distribution of primary particles in the plasma of welding fume: Coalescence of nuclei. J. Aerosol Sci. 67, 13 (2014).

37. C. Seigneur, A.B. Hudischewskyj, J.H. Seinfeld, K.T. Whitby, E.R. Whitby, J.R. Brock, H.M. Barnes. Simulation of aerosol dynamics: A comparative review of mathematical models. Aerosol Sci. Technol. 5, 205 (1986).

38. E.R. Whitby, P.H. McMurry. Modal aerosol dynamics modeling. Aerosol Sci. Technol. 27, 673 (1997).

39. P.R. Estrada, J.N. Cuzzi. Solving the coagulation equation by the moments method. Astrophys. J. 682, 515 (2008).

40. T.L. Chan, Y.H. Liu, C.K. Chan. Direct quadrature method of moments for the exhaust particle formation and evolution in the wake of the studied ground vehicle. J. Aerosol Sci. 41, 553 (2010).

41. E.R. Cohen, E.U. Vaughan. Approximate solution of the equations for aerosol agglomeration. J. Colloid Interface Sci. 35, 612 (1971).

42. M. Yu, J. Lin, T. Chan. A new moment method for solving the coagulation equation for particles in Brownian motion. Aerosol Sci. Technol. 42, 705 (2008).

43. Q. Shu, Y. Yang, Y. Zhai, D.M. Sun, H.J. Xiang, X.G. Gong. Size-dependent melting behavior of iron nanoparticles by replica exchange molecular dynamics. Nanoscale 4, 6307 (2012).

44. V.I. Vishnyakov, S.A. Kiro, M.V. Oprya, O.D. Chursina, A.A. Ennan. Numerical and experimental study of the ISSN 2071-0194. Ukr. J. Phys. 2019. Vol. 64, No. 5 
fume chemical composition in gas metal arc welding. Aerosol Sci. Engin. 2, 109 (2018).

45. M.K. Wu, S.K. Friedlander. Enhanced power law agglomerate growth in the free molecule regime. J. Aerosol Sci. 24, 273 (1992).

46. V.I. Vishnyakov, S.A. Kiro, M.V. Oprya, A.A. Ennan. Coagulation of charged particles in self-organizing thermal plasmas of welding fumes. J. Aerosol Sci. 76, 138 (2014).

47. Ch. Hagwood, Yu. Sivathanu, G. Mulholland. The DMA transfer function with Brownian motion a trajectory/Monte-Carlo approach. Aerosol Sci. Technol. 30, 40 (1999).

48. M.L. Eggersdorfer, S.E. Pratsinis. The structure of agglomerates consisting of polydisperse particles. Aerosol Sci. Technol. 46, 347 (2012).

49. M. Miettinen, T. Torvela, J.T.T. Leskinen. Physicochemical characterization of aerosol generated in the gas tungsten arc welding of stainless steel. Ann. Occup. Hyg. 60, 960 (2016).

50. V.I. Vishnyakov, S.A. Kiro, M.V. Oprya, A.A. Ennan. Charge distribution of welding fume particles after charging by corona ionizer. J. Aerosol Sci. 94, 9 (2016).

Received 8.07.18
B.I. Вишняков, С.А. Кіро,

М.В. Опря, О.Д. Чурсіна, А.А. Эннан

ФОРМУВАННЯ ЧАСТИНОК

У ПЛАЗМІ ЗВАРЮВАЛЬНОГО АЕРОЗОЛЮ:

ЧИСЕЛЬНЕ МОДЕЛЮВАННЯ І ЕКСПЕРИМЕНТ

$\mathrm{P}$ е $з$ ю м е

Шляхом чисельного моделювання еволюції плазми досліджується формування частинок у плазмі зварювального аерозолю, що утворюється при зварюванні металів у захисному газі. Модель еволюції плазми зварювального аерозолю включає такі процеси: емісію пари із зони дуги та їі змішування з захисним газом, утворення та зростання зародків за рахунок конденсації пари і коалесценції, отвердіння рідких крапель з утворенням первинних частинок, коагуляцію первинних частинок з утворенням інгаляційних частинок зварювального аерозолю у зоні дихання зварників. Результати чисельного моделювання порівнюються 3 експериментальними даними щодо питомої поверхні, хімічного складу та залежності розміру інгаляційних частинок від температури захисного газу. 